\title{
Combined effect of 2-5A-linked antisense against telomerase RNA and conventional therapies on human malignant glioma cells in vitro and in vivo
}

\author{
EIJI IWADO ${ }^{1}$, SHIGERU DAIDO $^{1}$, YASUKO KONDO $^{1}$ and SEIJI KONDO ${ }^{1-3}$ \\ ${ }^{1}$ Department of Neurosurgery, The University of Texas M.D. Anderson Cancer Center, Houston; \\ ${ }^{2}$ Department of Neurosurgery, The Baylor College of Medicine, Houston; ${ }^{3}$ Program in Molecular Pathology, \\ The University of Texas Graduate School of Biomedical Science at Houston, Houston, TX 77030, USA
}

Received May 3, 2007; Accepted June 18, 2007

\begin{abstract}
We recently showed that therapy with 2'-5'-oligoadenylate (2-5A)-linked antisense against human telomerase RNA component (2-5A-anti-hTR) is a novel telomerasetargeting strategy against malignant gliomas. In this study, we investigated conventional chemotherapeutic agents and $\gamma$-irradiation (IR) to determine whether they could augment the efficacy of 2-5A-anti-hTR against these tumors in vitro and in vivo. Treatment with 2-5A-anti-hTR inhibited the viability of U373-MG and U87-MG malignant glioma cells in a dose-dependent manner; the antitumor effect resulted from induction of apoptosis. Also, telomerase-positive astrocytes with oncogenic Ras were more sensitive to 2-5A-antihTR than were those without oncogenic Ras. In addition, we sought to determine the combined effect of 2-5A-antihTR with N, N'-bis (2-chloroethyl)-N-nitrosourea (BCNU), cisplatin (CDDP), paclitaxel (PTX), temozolomide (TMZ), or IR. When we administered the combination treatments on the same day, PTX and IR showed a greater combined effect with 2-5A-anti-hTR on both tumor cell lines than did BCNU, CDDP and TMZ. However, all of the combination regimens were synergistic when we first treated tumor cells with 2-5Aanti-hTR for $24 \mathrm{~h}$ and then exposed them to the conventional treatments. Apoptosis-inducing agents (CDDP and PTX) but not autophagy-inducing therapies (TMZ and IR) enhanced the incidence of apoptosis caused by 2-5A-anti-hTR. Lastly, we observed a combinatorial effect of 2-5A-anti-hTR and TMZ in vivo in subcutaneous U87-MG tumors in nude mice. Interestingly, treatment with TMZ increased the incidence of apoptosis in subcutaneous tumor cells treated with 2-5A-antihTR. These results suggest that 2-5A-anti-hTR is preferable in combination with established cancer therapies.
\end{abstract}

Correspondence to: Dr Seiji Kondo, Department of Neurosurgery, Unit BSRB 1004, The University of Texas M.D. Anderson Cancer Center, 1515 Holcombe Blvd., Houston, TX 77030, USA

E-mail: seikondo@mdanderson.org

Key words: apoptosis, 2-5A antisense, telomerase, glioma

\section{Introduction}

Malignant gliomas, including glioblastoma, are among the most devastating neoplasms (1). Although randomized trials have established the efficacy of radiotherapy for malignant gliomas, the addition of chemotherapy to radiotherapy did not result in a significant increase in survival rates (2). A recent clinical trial showed enhancement of survival in patients with newly diagnosed glioblastoma treated with the novel chemotherapeutic agent temozolomide (TMZ) together with radiation (3). However, the effectiveness of this combination was still modest. Therefore, exploration of new strategies for the treatment of malignant gliomas is needed.

Telomerase, an RNA-protein complex, adds hexameric repeats of 5'-TTAGGG-3' to the ends of telomeres to compensate for their progressive loss (4-6). Telomerase activity, which is generally undetectable in normal cells, is detectable in tumor cells in approximately $90 \%$ of all tumors $(7,8)$. Telomerase activity is quite frequently detected in malignant gliomas (9). Specifically, telomerase activity is detected in 0 to $83 \%$ of World Health Organization Grade II gliomas. Furthermore, $25-100 \%$ of Grade III (anaplastic astrocytomas) and $53-100 \%$ of Grade IV (glioblastoma) malignant gliomas have telomerase activity. Additionally, researchers showed that patients with telomerase-negative glioblastomas had better survival durations than did those with telomerasepositive glioblastomas (10). In contrast, normal brain tissues do not have telomerase activity, whereas human embryonic neural precursor cells have detectable telomerase activity only at low levels (11). Therefore, telomerase is considered to be very attractive not only as a useful prognostic and diagnostic marker for malignant gliomas but also for targeted therapy for these tumors.

Based on the observations described above, we previously hypothesized that inhibition of telomerase activity could be a new strategy for the management of malignant gliomas (9). To pursue this hypothesis, we adopted the 2'-5'-oligoadenylate (2-5A) system, which is a novel technology that exploits the body's natural antiviral defense by recruiting RNase L $(12,13)$. RNase $\mathrm{L}$ is an endoribonuclease that functions in the interferon-regulated 2-5A system to degrade viral and cellular single-stranded RNAs. It is converted from 
a silent to an active form upon binding to 2-5A. To activate RNase $\mathrm{L}$ and also direct it to a specific RNA target, $2-5 \mathrm{~A}$ is attached through linkers to the 5 ' terminus of an antisense oligonucleotide, creating 2-5A antisense oligonucleotide. Researchers have targeted this system against many different RNAs involved in human disease, including respiratory syncytial virus mRNA (13) and $b c l / a b l$ mRNA in chronic myelogenous leukemia (14).

Because RNase L is present in most mammalian cells, application of this technology may be a powerful method of controlling gene expression. Therefore, we decided to synthesize 2-5A antisense against human telomerase RNA (2-5A-anti-hTR). As we and others previously demonstrated, treatment with 2-5A-anti-hTR degraded hTR, inhibited telomerase activity, and consequently induced apoptosis in malignant glioma, prostate cancer, bladder cancer, cervical cancer, and ovarian cancer cells (15-20). Furthermore, this cell death was caspase-dependent and telomere lengthindependent (17-19). Moreover, intratumoral injection of 25A-anti-hTR was effective against subcutaneous and intracerebral tumors in nude mice (15-19). In addition, the in vitro and in vivo effect of 2-5A-anti-hTR was significantly enhanced by combining it with cisplatin (CDDP) or a recombinant adenovirus carrying p53 (Ad5CMV-p53) $(21,22)$. These findings indicate that targeting telomerase RNA with 2-5A-anti-hTR may be an effective and novel approach to treating telomerase-positive tumors. Because normal brain tissue cells do not express telomerase, malignant gliomas are considered among the best candidates for therapy with 2-5A-anti-hTR. Therefore, in the present study, we investigated the therapeutic effect of 2-5A-anti-hTR in combination with the chemotherapeutic agents N, N'-bis (2chloroethyl)-N-nitrosourea (BCNU), CDDP, paclitaxel (PTX), and TMZ and with $\gamma$-irradiation (IR) to further develop 2-5A-anti-hTR as a novel therapy for human malignant gliomas.

\section{Materials and methods}

Reagents. CDDP and BCNU were purchased from Sigma Chemical Co. (St. Louis, MO). TMZ was purchased from the pharmacy at The University of Texas M.D. Anderson Cancer Center (Houston, TX). PTX was purchased from Hande Tech Development (Houston, TX).

Cell culture. U87-MG and U373-MG human malignant glioma cells were obtained from the American Type Culture Collection (Manassas, VA, USA). Human astrocytes expressing telomerase with or without oncogenic Ras (NHA/ hTERT/Ras or NHA/hTERT) (23) were kindly provided by Dr Kenneth Aldape (M.D. Anderson Cancer Center). Cells were cultured in DMEM supplemented with $10 \%$ fetal bovine serum (Invitrogen, Carlsbad, CA), $100 \mathrm{U} / \mathrm{ml}$ penicillin (Invitrogen), and $2.5 \mu \mathrm{g} / \mathrm{ml}$ fungizone (Invitrogen) at $37^{\circ} \mathrm{C}$ in $5 \% \mathrm{CO}_{2}$.

Synthesis of 2-5A-anti-hTR. The antisense against hTR was selected as described previously (15). Briefly, the 2-5A antisense oligonucleotide was targeted to the region between residues 76 and 94, because this region was predicted to be the most open by the MFOLD computer program. The antisense sequence was 5'-GCG CGG GGA GCA AAA GCA C-3'. The chimeric oligonucleotides were synthesized at Sigma-Genosys (Woodlands, TX) using a modification of spacer 19 instead of a butanediol linker to link 2-5A to the oligonucleotides.

Cell viability assay. The cytotoxic effect of 2-5A-anti-hTR on cultured cells was determined using a trypan blue dye exclusion. The cells were seeded at $2 \times 10^{3}$ cells/well $(0.1 \mathrm{ml})$ in 96-well plates and incubated overnight at $37^{\circ} \mathrm{C}$. Oligonucleotides and Lipofectamine (Invitrogen) were then added to the wells every $24 \mathrm{~h}$ in the presence or absence of chemotherapeutic agents or IR. Cells treated with vehicle alone were considered to be $100 \%$ viable.

Cell cycle assay. For cell cycle analysis, tumor cells treated as described above were trypsinized, fixed with $70 \%$ ethanol, and stained with propidium iodide using a flow cytometry reagent set (Roche Applied Science, Indianapolis, IN) as described previously $(15,16)$. Samples were analyzed for DNA content using a FACScan flow cytometer and the CellQuest software program (Becton-Dickinson, San Jose, CA).

Hoechst 33258 DNA staining. The nuclei of cells were stained with Hoechst 33258 to detect chromatin condensation and nuclear fragmentation. Specifically, cells fixed with $4 \%$ paraformaldehyde were stained with Hoechst $33258(0.5 \mu \mathrm{g} / \mathrm{ml})$ for $15 \mathrm{~min}$. Two hundred cells were counted and scored for the incidence of apoptotic chromatin changes under a fluorescence microscope.

Detection of autophagy. LC3, a mammalian homologue of Apg8p, is recruited to the autophagosome membrane during autophagy (24). Green fluorescent protein (GFP)-tagged LC3-expressing cells were used to demonstrate induction of autophagy. GFP-LC3 cells presented a diffuse distribution under control conditions, whereas a punctate pattern of GFP-LC3 expression was increased in number and fluorescence intensity by autophagy. Therefore, using a GFP-LC3 expression vector kindly provided by Dr Noboru Mizushima (Tokyo Medical and Dental University, Tokyo, Japan), the involvement of LC3 in tumor cells treated with the 2-5Aanti-hTR in the presence or absence of conventional cancer treatment was analyzed as described previously (25). Tumor cells were transfected with the GFP-LC3 expression vector using FuGENE 6 transfection reagent (Roche Applied Science). After overnight culture, cells were treated with 2-5A-anti-hTR with or without other treatments, fixed with $4 \%$ paraformaldehyde, and examined under a fluorescence microscope.

Animal studies. U87-MG cells $\left(1 \times 10^{6}\right.$ cells in $20 \mu 1$ of serumfree DMEM) were inoculated subcutaneously into the right flank of 5 to 10 -week-old female nude mice (five mice in each treatment group). The resulting tumor growth was measured daily using calipers. Tumor volume was calculated as $\left(\mathrm{Lx} \mathrm{W}^{2}\right) / 2$, in which $\mathrm{L}$ is the length in millimeters and $\mathrm{W}$ is the width in millimeters, as described previously $(15,16)$. When the tumors reached a mean volume of $70-100 \mathrm{~mm}^{3}$, intratumoral injection of 2-5A-anti-hTR was initiated. 
A

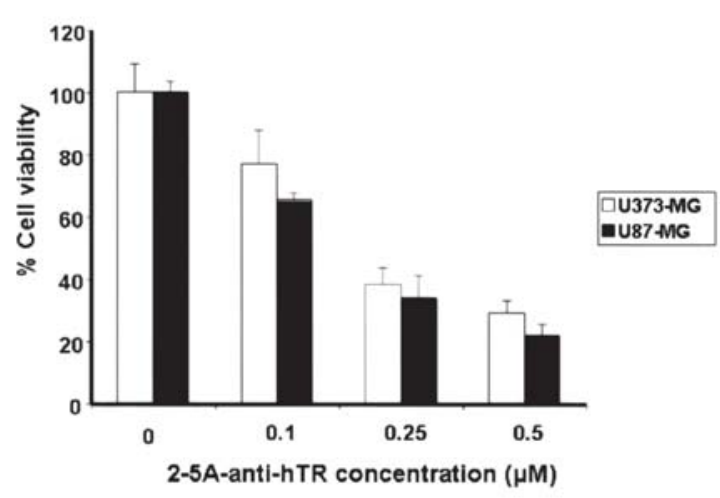

C

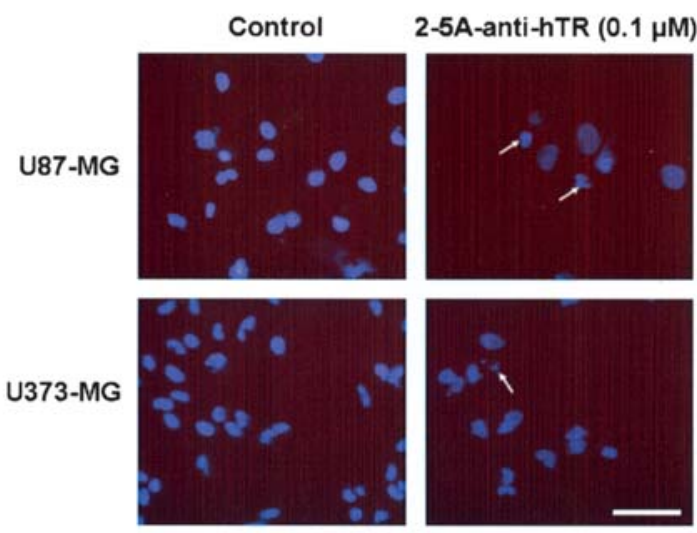

B

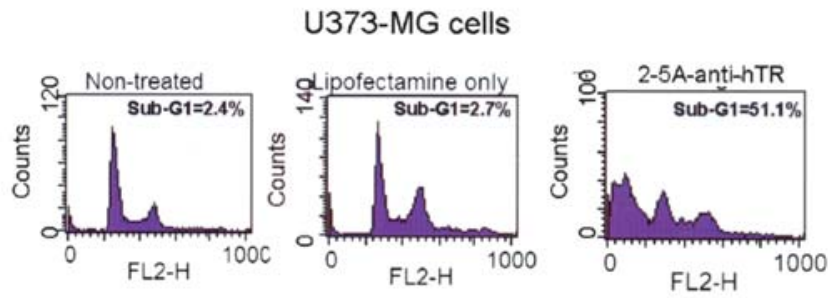

D

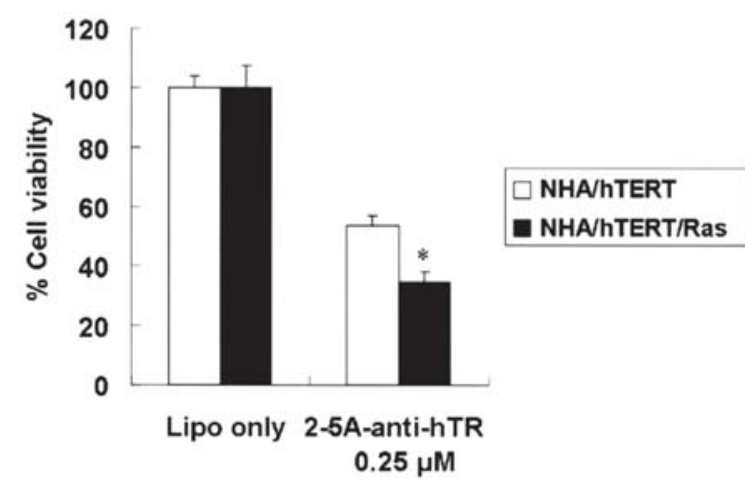

Figure 1. Effect of 2-5A-anti-hTR on malignant glioma cells. (A) Effect of 2-5A-anti-hTR on the viability of U373-MG and U87-MG cells. Tumor cells $\left(2 \times 10^{3}\right)$ were seeded in the wells of 96 -well plates and incubated overnight at $37^{\circ} \mathrm{C}$. Treatment with $2-5 \mathrm{~A}$-anti-hTR $(0.1-0.5 \mu \mathrm{M})$ with Lipofectamine $(0.4 \mu \mathrm{l} / 100 \mu \mathrm{l})$ was performed every $24 \mathrm{~h}$ for 3 days. Tumor cells were trypsinized, and the viable cells were counted. The results shown are the means $\pm \mathrm{SD}$. (B) Effect of 2-5A-anti-hTR on the cell cycle. U373-MG cells treated with $2-5 \mathrm{~A}$-anti-hTR $(0.5 \mu 1 \mathrm{M})$ with Lipofectamine $(0.4 \mu 1 / 100 \mu 1)$ every $24 \mathrm{~h}$ for 3 days were analyzed for the cell cycle. (C) Induction of apoptosis in malignant glioma cells by treatment with 2-5A-anti-hTR. After treatment with 2-5A-anti-hTR $(0.1 \mu \mathrm{M})$ every $24 \mathrm{~h}$ for 3 days, nuclei were stained with Hoechst 33258 to detect apoptotic cells. The arrows indicate representative apoptotic cells. Bar, $50 \mu \mathrm{m}$. (D) Effect of 2-5A-anti-hTR on NHA/hTERT with or without Ras. NHA/hTERT and NHA/hTERT/Ras cells $\left(2 \times 10^{3}\right)$ were seeded in the wells of 96-well plates and incubated at $37^{\circ} \mathrm{C}$. Treatment with 2 -5A-anti-hTR $(0.1-0.5 \mu \mathrm{M})$ with Lipofectamine $(0.4 \mu 1 / 100 \mu 1)$ was performed every $24 \mathrm{~h}$ for 3 days. Cells were trypsinized and the viable cells were counted. The results shown are the means $\pm \mathrm{SD}$. ${ }^{\mathrm{P}}<0.05$.

Specifically, 2-5A-anti-hTR ( $1 \mathrm{nmol} / 20 \mu 1$ sterile water) with Lipofectamine $(0.3 \mu \mathrm{l})$ was injected directly into the tumors every $24 \mathrm{~h}$ over 10 days (days $0-9)$. Also, TMZ (7.5 mg/kg) was administered into the peritoneal cavities of the mice over 9 days (days 1-9). The tumor volume was then measured every other day using calipers. Mice were euthanized by exposure to $\mathrm{CO}_{2}$ on day 10 . Their tumors were then removed, snap-frozen, and kept at $-80^{\circ} \mathrm{C}$ until use. Tumor specimens were sliced to a thickness of 10-20 $\mu \mathrm{m}$ using a cryostat, mounted on glass slides, fixed with $4 \%$ paraformaldehyde in PBS, and processed for immunohistochemical staining and terminal deoxynucleotidyl transferase-mediated dUTP nick end labeling (TUNEL) staining (Oncor, Inc., Gaithersburg, MD, USA), according to the manufacturer's instructions. Animal studies were performed in the veterinary facilities at M.D. Anderson in accordance with institutional, state, and federal regulations and institutional and international ethics guidelines for the care and use of experimental animals.

Statistical analysis. Data were expressed as the mean \pm standard deviation (SD). Statistical analysis was performed using Student's t-test (two-tailed). The combined effect of 2-5A-anti-hTR and TMZ or IR was analyzed using a combination index (CI) isobologram with the Calcusyn software program (Biosoft, Ferguson, MO), as described previously (26).

\section{Results and Discussion}

Effect of 2-5A-anti-hTR on malignant glioma cells. To evaluate the effectiveness of 2-5A-anti-hTR against malignant glioma cells, we treated U87-MG and U373-MG cells with $2-5 \mathrm{~A}$-anti-hTR in the range between 0.1 and $0.5 \mu \mathrm{M}$ in the presence of Lipofectamine $(0.4 \mu 1 / 100 \mu 1$ DMEM) every $24 \mathrm{~h}$ for 3 days. We based these optimized treatment conditions on previous investigations $(16,17)$. As shown in Fig. 1A, treatment with 2-5A-anti-hTR inhibited the viability of both U87-MG and U373-MG cells in a dose-dependent manner; $0.1 \mu \mathrm{M} 2-5 \mathrm{~A}-$ anti-hTR reduced the cell viability to $76 \%$ in U373-MG cells and 65\% in U87-MG cells, whereas $0.5 \mu \mathrm{M} 2-5 \mathrm{~A}$-anti-hTR reduced the cell viability to $29 \%$ in U373-MG cells and 22\% in U87-MG cells. Based on these 

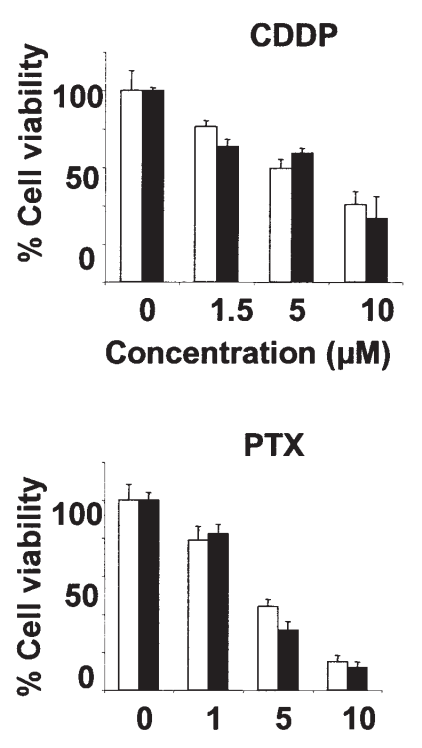

Concentration (nM)
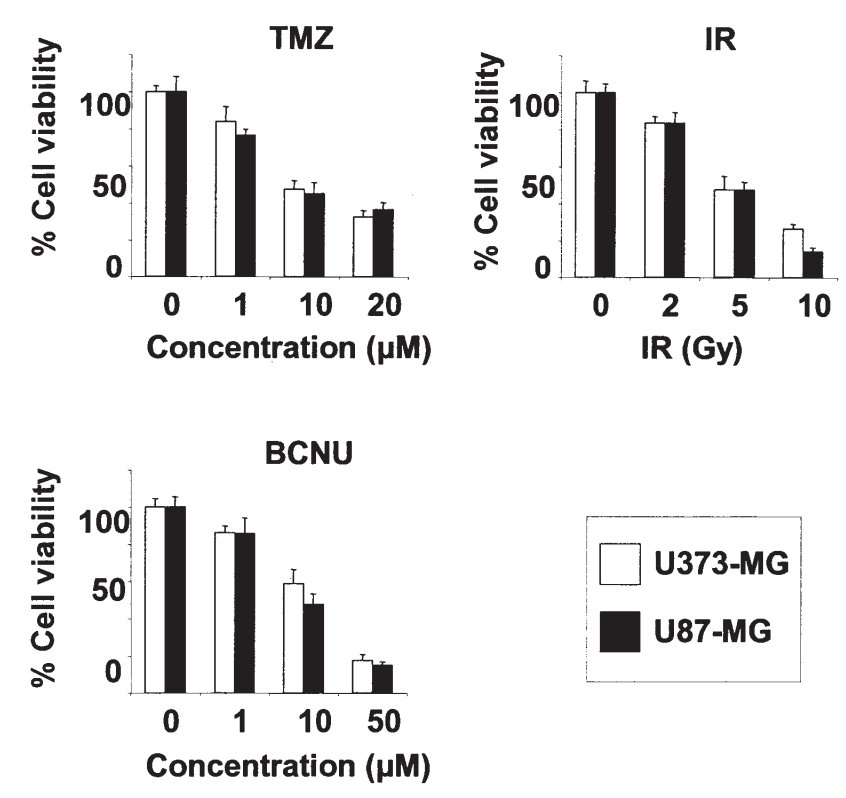

Figure 2. Effect of chemotherapeutic agents and IR on the viability of malignant glioma cells. U373-MG and U87-MG cells were seeded at 2x10 3 cells/well in 96-well plates and incubated overnight at $37^{\circ} \mathrm{C}$. After treatment with CDDP $(0,1.5,5$, or $10 \mu \mathrm{M})$, TMZ $(0,1,10$, or $20 \mu \mathrm{M})$, IR $(0,2,5$, or $10 \mathrm{~Gy})$, PTX $(0,1,5$, or $10 \mathrm{nM})$, or BCNU $(0,1,10$, or $50 \mu \mathrm{M})$ for 3 days, tumor cells were trypsinized and the viable cells were counted. The results shown are the means \pm SD.

data, we used $0.1 \mu \mathrm{M}$ 2-5A-anti-hTR for combination treatment with chemotherapeutic agents and IR as described below.

Induction of apoptosis in 2-5A-anti-hTR-treated malignant glioma cells. To determine whether 2-5A-anti-hTR that we synthesized with a different linker induces apoptosis, we measured the percentage of subG1 population, which is characteristic of apoptosis. DNA flow cytometry revealed that the percentage of cells in the sub-G1 phase increased from 2.4 to $51.1 \%$ after treatment of U373-MG cells with 2-5A-anti-hTR (Fig. 1B). Furthermore, we stained the nuclei of treated U87-MG and U373-MG cells with Hoechst 33258 to determine whether apoptotic morphology is induced by 2-5A-anti-hTR. As shown in Fig. 1C, the majority of tumor cells treated with 2-5A-anti-hTR were apoptotic. These results indicated that 2-5A-anti-hTR induces apoptosis in malignant glioma cells.

Effect of 2-5A-anti-hTR on genetically modified human astrocytes with telomerase activity and/or an oncogenic Ras gene. In our previous studies, treatment with 2-5A-anti-hTR induced cell death in telomerase-positive malignant glioma cells $(15,16)$. In contrast, telomerase-negative astrocytes were insensitive to this treatment, although all of the cells expressed hTR, which is a target of 2-5A-anti-hTR. These observations prompted us to hypothesize that the cytotoxicity of 2-5A-anti-hTR depends on tumorigenicity as well as telomerase activity. To test our hypothesis, we compared the effect of 2-5A-anti-hTR on tumorigenic astrocytes expressing telomerase and oncogenic Ras (NHA/hTERT/ Ras) with that on non-tumorigenic astrocytes expressing telomerase alone (NHA/hTERT). These astrocytes were genetically established to demonstrate the development of malignant gliomas (23). To immortalize human astrocytes, hTERT and human papillomavirus E6/E7 (to inactivate both p53 and pRb) genes were introduced by retroviral transfer. Although NHA/hTERT cells that escaped from senescence can grow indefinitely in culture, anchorage-independent growth of these cells as transformed cells in soft agar and as tumors in animals was undetectable. After introduction of an oncogenic Ras gene (H-Ras V12), NHA/hTERT/Ras cells acquired tumorigenicity. As shown in Fig. 1D, NHA/ hTERT/Ras cells were more sensitive to 2-5A-anti-hTR than NHA/hTERT were $(\mathrm{P}<0.05)$. These results indicated that the cytotoxic effect of 2-5A-anti-hTR may depend not only on telomerase activity but also on tumorigenicity, suggesting that 2-5A-anti-hTR initiates the tumor-specific cell death pathway.

Effect of chemotherapeutic agents and IR on the viability of malignant glioma cells. To determine the effect of CDDP, TMZ, PTX, BCNU and IR on the viability of U373-MG and U87-MG cells, we treated these cells with them at various concentrations and doses over 3 days. As shown in Fig. 2, both cell lines showed similar dose-dependent sensitivity to these treatments. Treatment with $1.5 \mu \mathrm{M}$ CDDP reduced the cell viability to 81 and $70 \%$ in U373-MG and U87-MG cells, respectively. Treatment with $\mathrm{TMZ}$ at $1 \mu \mathrm{M}$ reduced the cell viability to 83 and $76 \%$ in U373-MG and U87-MG cells, respectively. Administration of 2 Gy of IR reduced the cell viability to $83 \%$ in both U373-MG and U87-MG cells. Exposure to $1 \mathrm{nM}$ PTX reduced the cell viability to 79 and $82 \%$ in U373-MG and U87-MG cells, respectively. Finally, treatment with $1 \mu \mathrm{M}$ BCNU reduced the cell viability to 86 and $85 \%$ in U373-MG and U87-MG cells, respectively. We used these concentrations and doses (approximately the $80 \%$ inhibitory effects) for combination treatments with 2-5A-anti-hTR.

Combined effect of 2-5A-anti-hTR with chemotherapeutic agents and IR on the viability of malignant glioma cells. 

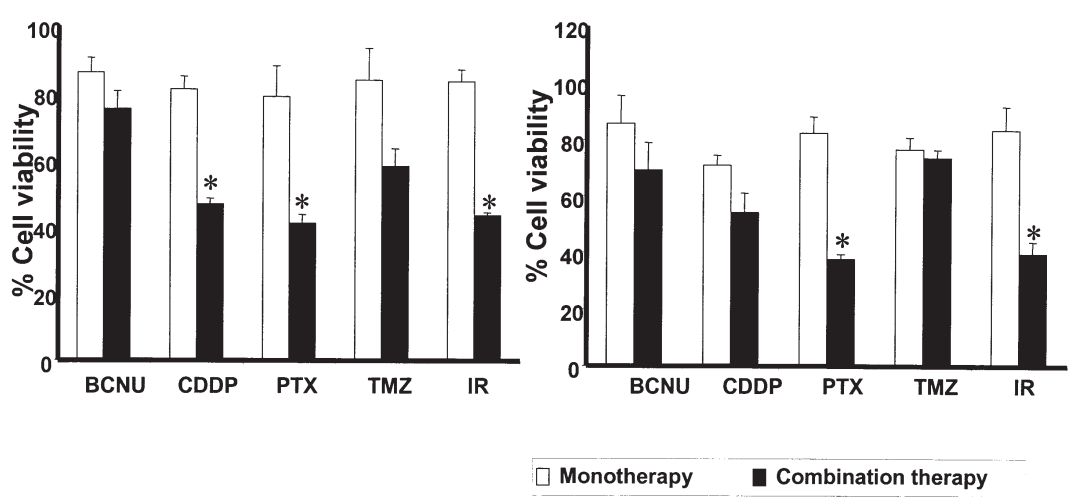

B

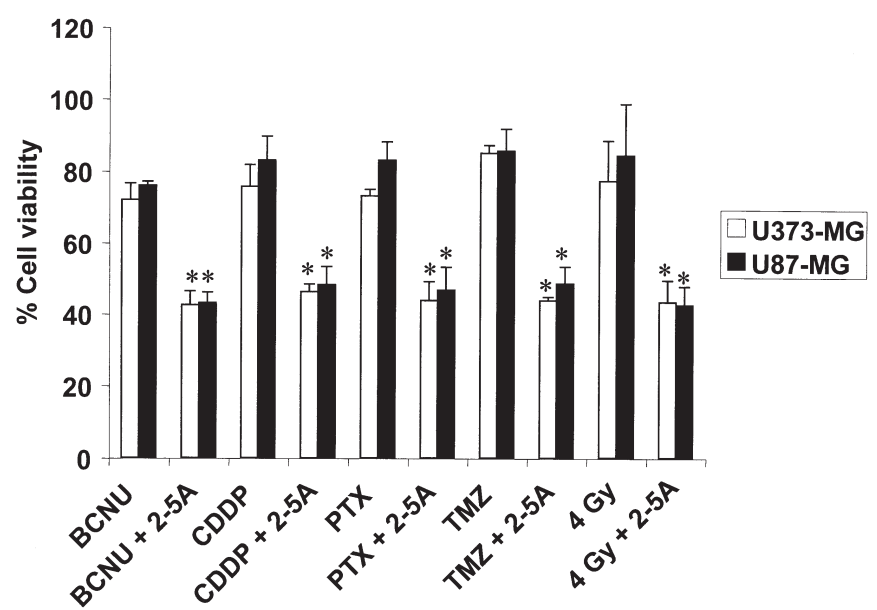

C
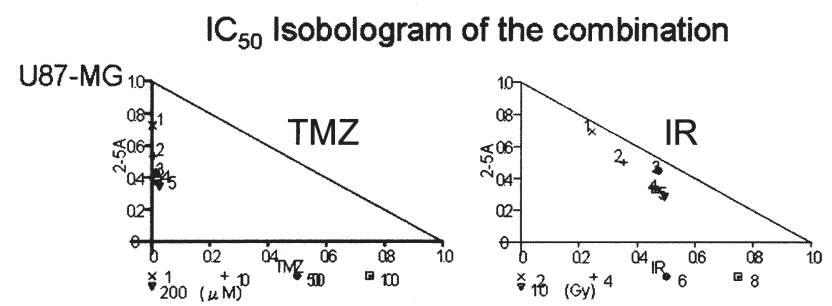

U373-MG

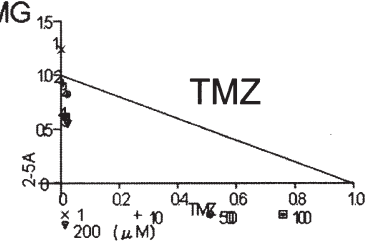

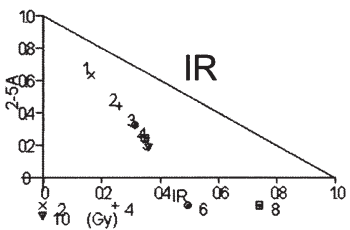

Figure 3. Combined effect of 2-5A-anti-hTR with chemotherapeutic agents and IR on the viability of malignant glioma cells. (A) Concurrent combination treatment. Cells were treated with $0.1 \mu \mathrm{M} 2-5 \mathrm{~A}$-anti-hTR every $24 \mathrm{~h}$ over 3 days starting on day 0 with or without BCNU ( $1 \mu \mathrm{M})$, CDDP (1.5 $\mu \mathrm{M})$, PTX $(1 \mathrm{nM})$, TMZ $(1 \mu \mathrm{M})$, or IR ( $2 \mathrm{~Gy})$ on day 0 for $24 \mathrm{~h}$. Tumor cells were then trypsinized and the viable cells were counted. The results shown are the means \pm $\mathrm{SD}$. ${ }^{*} \mathrm{P}<0.05$. (B) Sequence-changed combination treatment. One day after treatment with $0.1 \mu \mathrm{M} 2-5 \mathrm{~A}-\mathrm{anti}$-hTR, tumor cells were treated with BCNU $(1 \mu \mathrm{M}), \mathrm{CDDP}(1.5 \mu \mathrm{M})$, PTX $(1 \mathrm{nM})$, TMZ $(1 \mu \mathrm{M})$, or IR (2 Gy). Next, treatment with 2-5A-anti-hTR was repeated on days 1, 2 and 3. WST-1 assay was then performed. The results shown are the means $\pm \mathrm{SD} .{ }^{*} \mathrm{P}<0.05$. (C) $\mathrm{IC}_{50}$ isobolograms of the combination treatments. U373-MG and U87-MG cells were treated with $0.1 \mu \mathrm{M} 2-5 \mathrm{~A}$-anti-hTER every $24 \mathrm{~h}$ over 3 days starting on day 0 with TMZ $(0-1,000 \mu \mathrm{M})$ or IR $(0-20 \mathrm{~Gy})$ on day 1 for $24 \mathrm{~h}$. The viable cells were then counted. In the isobolograms, the plots on the diagonal lines indicate that this combination was additive. The plots on the left under the line indicate that it was synergistic, and the plots on the right above the line indicate that it was antagonistic.

We also investigated 2-5A-anti-hTR to determine whether it enhances the effects of chemotherapy and radiotherapy on human malignant glioma. First, we treated U373-MG and U87-MG cells with 2-5A-anti-hTR and BCNU, CDDP, PTX, TMZ, or IR on the same day. As shown in Fig. 3A, CDDP, PTX, and IR exhibited a better combined effect with 2-5Aanti-hTR on U373-MG cells than BCNU and TMZ did $(\mathrm{P}<0.05$, respectively). In comparison, PTX and IR enhanced the effect of 2-5A-anti-hTR on U87-MG cells more than BCNU, CDDP and TMZ did. Namely, in the concurrent treatment regimens, PTX and IR showed a better combinatorial effect with 2-5A-anti-hTR than the other three conventional treatments did on both cell lines. Second, we changed the treatment sequence to optimize the combination regimens. After we first treated tumor cells with 2-5A-anti-hTR for $24 \mathrm{~h}$, we exposed them to conventional treatments. BCNU, CDDP, PTX, TMZ and IR all exhibited a strong combinatorial effect with 2-5A-anti-hTR on both U373-MG and U87-MG cells $(\mathrm{P}<0.05)$ (Fig. 3B). Previous investigations demonstrated that some cancer treatments inhibit telomerase activity (27-30).
Because the antitumor activity of 2-5A-anti-hTR depends on telomerase activity, treating tumor cells with 2-5A-antihTR until the telomerase activity in them is remarkably inhibited by conventional treatments may be beneficial. As expected, when we administered 2-5A-anti-hTR 1 day after administering the conventional therapies, the combined effects were largely diminished, supporting our speculation above.

Next, we evaluated these combined effects to determine whether they were synergistic or additive, especially for TMZ and IR, because these treatments are considered promising adjuvant therapies after surgery (3). We calculated the CI value and plotted the isobologram at the $50 \%$ inhibitory concentrations. As shown in Fig. 3C, all of the plots except one (1 $\mu \mathrm{M}$ TMZ with 2-5A-anti-hTR in U373MG) were synergistic in U373-MG and U87-MG for the combination of 2-5A-anti-hTR and TMZ or IR. These results suggested that 2-5A-anti-hTR synergistically sensitized both U373-MG and U87-MG to TMZ and IR. 

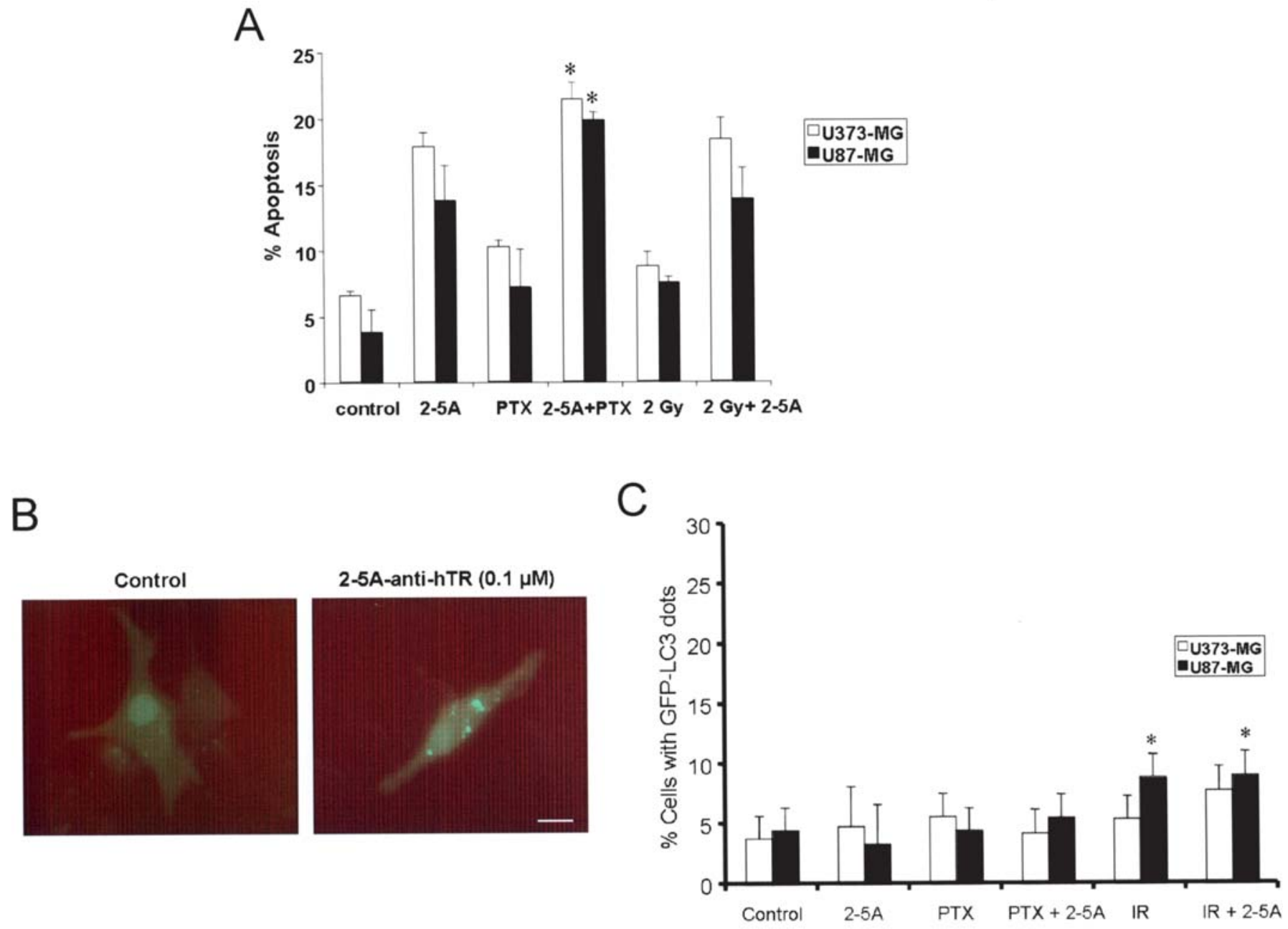

Figure 4. Induction of apoptosis and autophagy in malignant glioma cells by 2-5A-anti-hTR-based combination therapy. (A) Induction of apoptosis. U373-MG and U87-MG cells were treated with 2-5A-anti-hTR $(0.1 \mu \mathrm{M})$ every $24 \mathrm{~h}$ over 3 days starting on day 0 with or without PTX (1 nM) or IR (2 Gy) on day 1 for $24 \mathrm{~h}$. The nuclei were then stained with Hoechst 33258 to detect apoptotic cells. The results shown are the means \pm SD. ${ }^{*} \mathrm{P}<0.05$. (B) Detection of autophagy in malignant glioma cells treated with 2-5A-anti-hTR. U373-MG cells expressing GFP-LC3 were treated with 2-5A-anti-hTR (0.1 $\mu$ M) every $24 \mathrm{~h}$ over 3 days starting on day 0 . Bar, $20 \mu \mathrm{m}$. (C) Quantification of cells expressing GFP-LC3 dots in malignant glioma cells treated with 2-5A-anti-hTRbased combinations. The percentage of cells positive for GFP-LC3 dots was quantified by counting the number of cells showing the GFP-LC3 punctate pattern. The results shown are the means $\pm \mathrm{SD}$. ${ }^{*} \mathrm{P}<0.05$.

Detection of apoptosis and autophagy in malignant glioma cells treated with 2-5A-anti-hTR in the presence or absence of PTX, TMZ, or IR. Previously, malignant glioma cells underwent apoptosis after treatment with 2-5A-anti-hTR (Fig. 1B and C) and PTX (31), whereas cells underwent non-apoptotic autophagy after treatment with TMZ or IR $(32,33)$. Therefore, we sought to determine whether the combination treatments affected the induction of apoptosis caused by $2-5 \mathrm{~A}$-anti-hTR or induced autophagy. As shown in Fig. 4A, 6 and 3\% of untreated U373-MG and U87-MG cells, respectively, underwent apoptosis. Treatment with 2-5A-anti-hTR at $0.1 \mu \mathrm{M}$ for 3 days induced apoptosis in 16 and $13 \%$ of U373-MG and U87-MG cells, respectively. Also, treatment with PTX at $1 \mathrm{nM}$ induced apoptosis in 10 and $7 \%$ of U373-MG and U87-MG cells, respectively. As expected, combination treatment with $1 \mathrm{nM}$ PTX and $0.1 \mu \mathrm{M} 2-5 \mathrm{~A}-$ anti-hTER increased the percentage of apoptosis rate to 21 and $19 \%$ in U373-MG and U87-MG cells, respectively $(\mathrm{P}<0.05)$. However, IR at $2 \mathrm{~Gy}$, which induced apoptosis in 9 and $8 \%$ of U373-MG and U87-MG cells, respectively, did not affect the incidence of apoptosis caused by $2-5 \mathrm{~A}-$ anti-hTR. In addition, treatment with TMZ at $1 \mu \mathrm{M}$ induced apoptosis in 7 and 5\% of U373-MG and U87-MG cells, respectively, but did not increase the percentage of apoptotic cells when compared with treatment with 2-5A-anti-hTR.

Recent studies have discovered non-apoptotic autophagic cell death in cancer therapy $(31,34)$. Therefore, we sought to determine whether autophagy is induced in malignant glioma cells by 2-5A-anti-hTR with or without treatment with PTX, TMZ, or IR. As shown in Fig. 4B, U373-MG cells not treated with 2-5A-anti-hTR showed diffuse distribution of GFP, indicating that they were not autophagic. When we treated these cells with 2-5A-anti-hTR, very few cells showed a punctate pattern of GFP, indicating that they were autophagic cells. We then quantified the percentage of autophagic U373-MG and U87-MG cells. As shown in Fig. 4C, $<10 \%$ of U373-MG and U87-MG cells treated with 2-5A-anti-hTR, PTX, IR, or 2-5A-anti-hTR in combination with PTX or 


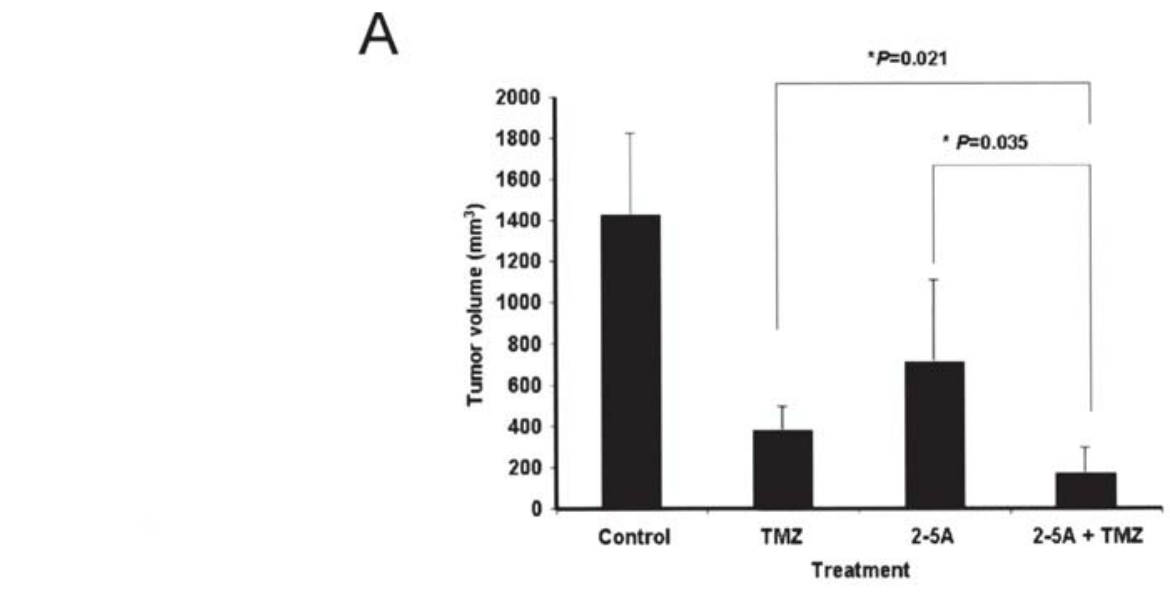

B

Control

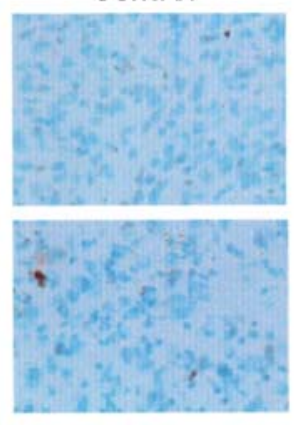

TMZ
2-5A

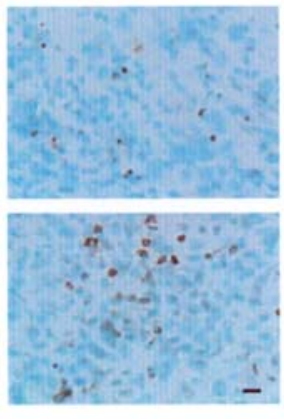

2-5A+TMZ
C

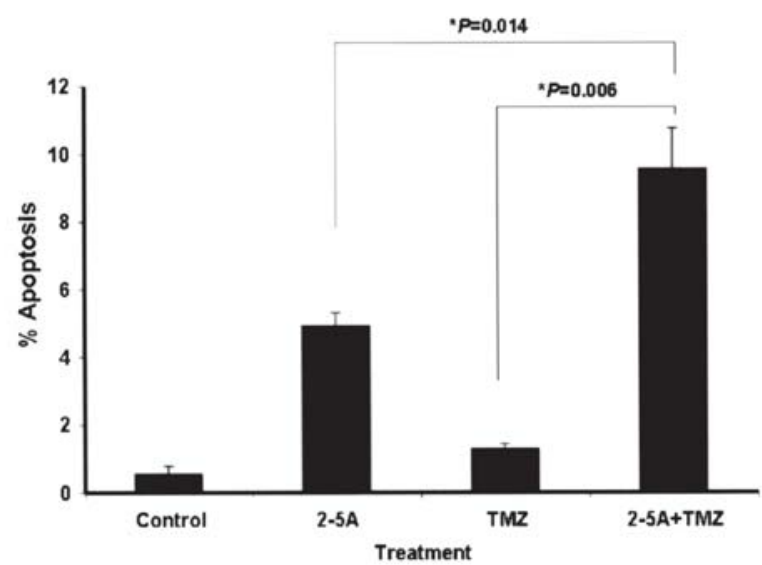

Figure 5. Effect of the combination of 2-5A-anti-hTR and TMZ on subcutaneous malignant gliomas. (A) Effect of the combination of 2-5A-anti-hTR and TMZ on tumor size. When the tumors reached a mean volume of $70-100 \mathrm{~mm}^{3}$, treatment was initiated. 2-5A-anti-hTR (1 nmol/20 $\mu 1 \mathrm{sterile}$ water) with Lipofectamine $(0.3 \mu \mathrm{l})$ was injected directly into the tumors every $24 \mathrm{~h}$ over 10 days (days $0-9)$. TMZ (7.5 mg/kg) was administered into the peritoneal cavities of the mice over 9 days (days 1-9). Tumor volume was measured every other day using calipers. The results shown are the means \pm SD. (B) Induction of apoptosis in subcutaneous tumors treated with 2-5A-anti-hTR or TMZ. Treated subcutaneous tumors were removed and fixed for TUNEL staining. Representative pictures are shown. Bar, $20 \mu \mathrm{m}$. (C) Quantification of TUNEL-positive cells in tumor specimens obtained from the mice that were treated with 2-5A-anti-hTR in the presence or absence of TMZ. Areas containing 100 cells were examined, and the TUNEL-positive cells were counted; three areas were chosen for each sample. The results shown are the means \pm SD.

IR had GFP-LC3 dots. Although IR at 2 Gy significantly induced autophagy in U87-MG cells $(9 \% ; \mathrm{P}<0.05$ when compared with control cells), the addition of 2-5A-anti-hTR did not affect induction of autophagy. Treatment with $\mathrm{TMZ}$ at $1 \mu \mathrm{M}$ also induced autophagy in U87-MG (16\%) and U373-MG (9\%) cells. However, treatment with the combination of TMZ and 2-5A-anti-hTR did not significantly increase the percentage of autophagic cells. These results indicated that 2-5A-anti-hTR induces apoptosis but not autophagy in malignant glioma cells.

Combinatorial effect of 2-5A-anti-hTR and TMZ in vivo. Because TMZ and IR showed a similar combined effect with 2-5A-anti-hTR on malignant glioma cells, we decided to explore the in vivo antitumor effect of 2-5A-anti-hTR in the presence or absence of TMZ. When subcutaneous xenografts derived from U87-MG cells in nude mice reached a mean volume of $70-100 \mathrm{~mm}^{3}$ (defined as day 0 ), we injected 2-5A-anti-hTR ( $1 \mathrm{nmol} / 20 \mu 1$ sterile distilled water) with Lipofectamine $(0.3 \mu 1)$ directly into the tumors daily from day 0 to day 9 . Also, we administered TMZ $(7.5 \mathrm{mg} / \mathrm{kg})$ into the peritoneal cavities of the mice daily from day 1 to day 9 . We measured the size of the resulting tumors every other day until day 10. As shown in Fig. 5A, mice treated with TMZ had tumors about $74 \%$ smaller than those in the control mice on day 10 (mean volume $=1427.0 \pm 100.0 \mathrm{~mm}^{3}$ in control mice and $379.3 \pm 26.6 \mathrm{~mm}^{3}$ in TMZ-treated mice; $\left.\mathrm{P}<0.01\right)$. Also, mice given 2-5A-anti-hTR had tumors about $50 \%$ smaller than those in the control mice on day 10 (mean volume = $711.7 \pm 9.9 \mathrm{~mm}^{3}$ in $2-5 \mathrm{~A}$-anti-hTR-treated mice; $\left.\mathrm{P}<0.01\right)$. Finally, mice given the combination of TMZ and 2-5Aanti-hTR had tumors about $88 \%$ smaller than those in the control mice on day 10 (mean volume $=172.7 \pm 12.1 \mathrm{~mm}^{3}$ in TMZ and 2-5A-anti-hTR-treated mice; $\mathrm{P}=0.021$, TMZ vs. 2-5A-anti-hTR plus TMZ; $\mathrm{P}=0.035$, 2-5A-anti-hTR vs. 2-5Aanti-hTR plus TMZ) (Fig. 5A).

We removed the subcutaneous tumors from the mice on day 10 and processed them for TUNEL staining. As shown in Fig. 5B, we detected TUNEL-positive cells mainly among tumor cells treated with 2-5A-anti-hTR alone or combined with TMZ. Our quantification of apoptosis incidence revealed that the apoptosis rate was $5 \%$ in $2-5 \mathrm{~A}$-anti-hTR-treated 
tumors, but $<2 \%$ in control- and TMZ-treated tumors (Fig. 5C). The apoptosis rate was 9\% in the TMZ- and 2-5Aanti-hTR-treated tumors $(\mathrm{P}=0.014$, compared with 2-5A-antihTR; $\mathrm{P}=0.006$, compared with TMZ). Although treatment with TMZ alone did not significantly induce apoptosis, it may have affected some factors that stimulate the apoptotic pathway directly or indirectly when combined with $2-5 \mathrm{~A}-$ anti-hTR. Further study is necessary to identify the molecular mechanisms underlying the discrepancy in in vitro and in vivo settings. These results indicated that treatment with the combination of TMZ and 2-5A-anti-hTR effectively inhibits the growth of malignant glioma cells in vivo through apoptosis.

In this study, we showed that treatment with 2-5A-antihTR induced apoptosis in malignant glioma cells within 3 days after the initiation of treatment. Treatment with 2-5Aanti-hTR in the presence of BCNU, CDDP and TMZ better enhanced the cell-killing effect when done sequentially rather than concurrently; treatment with 2-5A-anti-hTR in the presence of PTX and IR enhanced this effect at similar levels both concurrently and sequentially. The enhanced cellkilling effect resulted from apoptosis. In comparison, 2-5Aanti-hTR did not impair the autophagy induced by treatment with TMZ or IR. TMZ and IR, which are considered promising adjuvant therapies for malignant glioma, showed a synergistic combined effect with 2-5A-anti-hTR. In our animal xenograft model, TMZ enhanced the anti-tumor effect of 2-5Aanti-hTR via induction of apoptosis.

Accumulating evidence has raised considerable interest in telomerase inhibition as a potential cancer therapy (9). Recently, studies identified six subunits that make up the human telomerase complex: hTR (35), telomerase-associated protein 1 (TEP1) $(36,37)$, hTERT $(38,39)$, heat shock protein 90 (HSP90) (40), the molecular chaperone p23 (40), and dyskerin (41). hTR functions as a template for telomere elongation by telomerase. TEP1, which is homologous to the Tetrahymena telomerase component gene p80, is associated with RNA and protein binding. hTERT contains reverse transcriptase motifs and functions as the catalytic subunit of telomerase. HSP90 and p23 can bind to hTERT and contribute to telomerase activity. Dyskerin, which is the pseudouridine synthase component of the box H + ACA snoRNAs, also interacts with hTR. Three major subunits (hTR, TEP1, and hTERT) correlate with telomerase activity, whereas the association between telomerase activity and expression of HSP90, p23 and dyskerin remains unclear. Strategies for inhibition of telomerase activity have focused on antisense oligonucleotides against hTR and hTERT, inhibitors of reverse transcriptases, and small molecules able to interact with and stabilize four-stranded (G-quadruplex) structures formed by telomeric DNA $(28,35,42-45)$.

These investigations show that inhibition of telomerase activity suppresses the proliferation of cancer cells and the growth of tumor xenografts in animals, indicating that telomerase is a promising therapeutic target for cancer. However, one of the major limitations of targeting telomerase in tumors is that telomeric DNA must shorten considerably before tumor cells undergo cell death or senescence. In other words, there is a lag between the time telomerase is inhibited and the time telomeres of the cancer cells shorten sufficiently to exhibit a significant effect on cellular proliferation. Therefore, the lag must be shortened by modifying the telomerase inhibition approach or developing a telomerase inhibition system that induces cell death rapidly. As we and others recently showed, 2-5Aanti-hTR induces a cell-killing effect or apoptosis regardless of the telomere length, indicating the attractiveness of 2-5Aanti-hTR in cancer therapy.

\section{Acknowledgments}

We thank Dr Noboru Mizushima for the GFP-LC3 vector. We also thank E. Faith Hollingsworth for technical support and Donald R. Norwood for editing the manuscript. This study was supported in part by USPHS Grants CA088936 and CA108558 from the National Cancer Institute, a start-up fund from M.D. Anderson (to S.K.), a generous donation from the Anthony D. Bullock III Foundation (to Y.K., S.K.), and the Cancer Center Support (Core) Grant Shared Resources.

\section{References}

1. Reardon DA, Rich JN, Friedman HS and Bigner DD: Recent advances in the treatment of malignant astrocytoma. J Clin Oncol 24: 1253-1265, 2006.

2. Van den Bent MJ, Hegi ME and Stupp R: Recent developments in the use of hemotherapy in brain tumours. Eur J Cancer 42: 582-588, 2006.

3. Stupp R, Mason WP, van den Bent MJ, Weller M, Fisher B, Taphoorn MJ, Belanger K, Brandes AA, Marosi C, Bogdahn U, Curschmann J, Janzer RC, Ludwin SK, Gorlia T, Allgeier A, Lacombe D, Cairncross JG, Eisenhauer E, Mirimanoff RO, European Organisation for Research and Treatment of Cancer Brain Tumor and Radiotherapy Groups, and National Cancer Institute of Canada Clinical Trials Group: Radiotherapy plus concomitant and adjuvant temozolomide for glioblastoma. N Engl J Med 352: 987-996, 2005

4. Blackburn EH: Structure and function of telomeres. Nature 350: 569-573, 1991

5. Counter CM, Avilion AA, LeFeuvre CE, Stewart NG, Greider CW, Harley CB and Bacchetti S: Telomere shortening associated with chromosome instability is arrested in immortal cells which express telomerase activity. EMBO J 11: 1921-1929, 1992.

6. De Lange T: Activation of telomerase in a human tumor. Proc Natl Acad Sci USA 91: 2882-2885, 1994.

7. Kim NW, Piatyszek MA, Prowse KR, Harley CB, West MD, Ho PLC, Coviello GM, Wright WE, Weinrich SL and Shay JW: Specific association of human telomerase activity with immortal cell lines and cancer. Science 266: 2011-2015, 1994.

8. Broccoli D, Young JW and De Lange T: Telomerase activity in normal and malignant hematopoietic cells. Proc Natl Acad Sci USA 92: 9082-9086, 1995.

9. Komata T, Kanzawa T, Kondo Y and Kondo S: Telomerase as a therapeutic target for malignant gliomas. Oncogene 21: 656-663, 2002.

10. Hakin-Smith V, Jellinek DA, Levy D, Carroll T, Teo M, Timperley WR, McKay MJ, Reddel RR and Royds JA: Alternative lengthening of telomeres and survival in patients with glioblastoma multiforme. Lancet 361: 836-838, 2003.

11. Ostenfeld T, Caldwell MA, Prowse KR, Linskens MH, Jauniaux E and Svendsen CN: Human neural precursor cells express low levels of telomerase in vitro and show diminishing cell proliferation with extensive axonal outgrowth following transplantation. Exp Neurol 164: 215-226, 2000.

12. Maran A, Maitra RK, Kumar A, Dong B, Xiao W, Li G, Williams BRG, Torrence PF and Silverman RH: Blockage of NF-B signaling by selective ablation of an mRNA target by 2-5A antisense chimeras. Science 265: 789-792, 1994.

13. Cirino NM, Li G, Xiao W, Torrence PF and Silverman RH: Targeting RNA decay in respiratory syncytial virus infected cells with 2'->5'oligoadenylate-antisense. Proc Natl Acad Sci USA 94: 1937-1942, 1997. 
14. Maran A, Waller CF, Paranjape JM, Li G, Xiao W, Zhang K, Kalaycio ME, Maitra RK, Lichtin AE, Brugger W, Torrence PF and Silverman RH: 2',5'-Oligoadenylate-antisense chimeras cause RNase L to selectively degrade bcr/abl mRNA in chronic myelogenous leukemia cells. Blood 92: 4336-4343, 1998.

15. Kondo S, Kondo Y, Li G, Silverman RH and Cowell JK: Targeted therapy of human malignant glioma in a mouse model by $2-5 \mathrm{~A}$ antisense directed against telomerase RNA. Oncogene 16: 3323-3330, 1998.

16. Mukai S, Kondo Y, Koga S, Komata T, Barna BP and Kondo S: 2-5A antisense telomerase RNA therapy for intracranial malignant gliomas. Cancer Res 60: 4461-4467, 2000.

17. Yatabe N, Kyo S, Kondo S, Kanaya T, Wang Z, Maida Y, Takakura M, Nakamura M, Tanaka M and Inoue M: 2-5A antisense therapy directed against human telomerase RNA inhibits telomerase activity and induces apoptosis without telomere impairment in cervical cancer cells. Cancer Gene Ther 9: 624-630, 2002

18. Kondo Y, Koga S, Komata T and Kondo S: Treatment of prostate cancer in vitro and in vivo with $2-5 \mathrm{~A}$-anti-telomerase RNA component. Oncogene 19: 2205-2211, 2000.

19. Koga S, Kondo Y, Komata T and Kondo S: Treatment of bladder cancer cells in vitro and in vivo with 2-5A antisense telomerase RNA. Gene Ther 8: 654-658, 2000.

20. Kushner DM, Paranjape JM, Bandyopadhyay B, Cramer H, Leaman DW, Kennedy AW, Silverman RH and Cowell JK: 2-5A antisense directed against telomerase RNA produces apoptosis in ovarian cancer cells. Gynecol Oncol 76: 183-192, 2000.

21. Komata T, Kondo Y, Koga S, Ko SC, Chung LWK and Kondo S: Combination therapy of malignant glioma cells with 2-5Aantisense telomerase RNA and recombinant adenovirus p53. Gene Ther 7: 2071-2079, 2000.

22. Kondo Y, Komata $\mathrm{T}$ and Kondo S: Combination therapy of 2-5A antisense against telomerase RNA and cisplatin for malignant gliomas. Int J Oncol 18: 1287-1292, 2001.

23. Sonoda Y, Ozawa T, Hirose Y, Aldape KD, McMahon M Berger MS and Pieper RO: Formation of intracranial tumors by genetically modified human astrocytes defines four pathways critical in the development of human anaplastic astrocytoma. Cancer Res 61: 4956-4960, 2001

24. Kabeya Y, Mizushima N, Ueno T, Yamamoto A, Kirisako T, Noda T, Kominami E, Ohsumi Y and Yoshimori T: LC3, a mammalian homologue of yeast Apg8p, is localized in autophagosome membranes after processing. EMBO J 19: 5720-5728, 2000 .

25. Daido S, Kanzawa T, Yamamoto A, Takeuchi H, Kondo Y and Kondo S: Pivotal role of the cell death factor BNIP3 in ceramide-induced autophagic cell death in malignant glioma cells. Cancer Res 64: 4286-4293, 2004

26. Takeuchi H, Kondo Y, Fujiwara K, Kanzawa T, Aoki H, Mills GB and Kondo S: Synergistic augmentation of rapamycin-induced autophagy in malignant glioma cells by phospha-tidylinositol 3-phosphate kinase/protein kinase B Inhibitors. Cancer Res 65: 3336-3346, 2005.

27. Faraoni I, Turriziani M, Masci G, De Vecchis L, Shay JW, Bonmassar E and Graziani G: Decline in telomerase activity as a measure of tumor cell killing by antineoplastic agents in vitro. Clin Cancer Res 3: 579-585, 1997.

28. Chou WC, Hawkins AL, Barrett JF, Griffin CA and Dang CV: Arsenic inhibition of telomerase transcription leads to genetic instability. J Clin Invest 108: 1541-1547, 2001.

29. Lin Z, Lim S, Viani MA, Sapp M and Lim MS: Downregulation of telomerase activity in malignant lymphomas by radiation and chemotherapeutic agents. Am J Pathol 159: 711-719, 2001
30. Kanzawa T, Germano IM, Kondo Y, Ito H, Kyo S and Kondo S Inhibition of telomerase activity in malignant glioma cells correlates with their sensitivity to temozolomide. Br J Cancer 89: 922-929, 2003.

31. Kondo $\mathrm{Y}$ and Kondo S: Autophagy and cancer therapy Autophagy 2: 85-90, 2006

32. Kanzawa T, Germano IM, Komata T, Ito H, Kondo Y and Kondo S: Role of autophagy in temozolomide-induced cytotoxicity for malignant glioma cells. Cell Death Differ 11 : 448-457, 2004

33. Ito H, Daido S, Kanzawa T, Kondo S and Kondo $\mathrm{Y}$ : Radiationinduced autophagy is associated with LC3 and its inhibition sensitizes malignant glioma cells. Int J Oncol 26: 1401-1410, 2005.

34. Kondo Y, Kanzawa T, Sawaya R and Kondo S: Role of autophagy in cancer development and response to therapy. Nat Rev Cancer 5: 726-734, 2005.

35. Feng J, Funk WD, Wang SS, Weinrich SL, Avilion AA, Chiu CP, Adams RR, Chang E, Allsopp RC, Yu J, Le S, West MD, Harley CB, Andrews WH, Greider CW and Villeponteau B: The RNA component of human telomerase. Science 269: 1236-1241, 1995.

36. Harrington L, McPhail T, Mar V, Zhou W, Oulton R, Bass MB, Arruda I and Robinson MO: A mammalian telomerase-associated protein. Science 275: 973-977, 1997

37. Nakayama J, Saito M, Nakamura H, Matsuura A and Ishikawa F: TLP1: a gene encoding a protein component of mammalian telomerase is a novel member of WD repeats family. Cell 88 : 875-884, 1997.

38. Meyerson M, Counter CM, Eaton EN, Ellisen LW, Steiner P, Caddle SD, Ziaugra L, Beijersbergen RL, Davidpoff ML, Liu Q, Bacchetti S, Haber DA and Weinberg RA: hEST2, the putative human telomerase catalytic subunit gene, is upregulated in tumor cells and during immortalization. Cell 90: 785-795, 1997

39. Nakamura TM, Morin GB, Chapman KB, Weinrich SL, Andrews WH, Lingner J, Harley CB and Cech TR: Telomerase catalytic subunit homologs from fission yeast and human. Science 277: 955-959, 1997.

40. Holt SE, Aisner DL, Baur J, Tesmer VM, Dy M, Ouellette M, Trager JB, Morin GB, Toft DO, Shay JW, Wright WE and White MA: Functional requirement of p23 and Hsp90 in telomerase complexes. Genes Dev 13: 817-826, 1999.

41. Mitchell JR, Wood E and Collins K: A telomerase component is defective in the human disease dyskeratosis congenita. Nature 402: 551-555, 1999.

42. Kondo S, Tanaka Y, Kondo Y, Hitomi M, Barnett GH, Ishizaka Y, Liu J, Haqqi T, Nishiyama A, Villeponteau B, Cowell JK and Barna BP: Antisense telomerase treatment: induction of two distinct pathways, apoptosis and differentiation. FASEB J 12: 801-811, 1998

43. Hahn WC, Stewart SA, Brooks MW, York SG, Eaton E, Kurachi A, Beijersbergen RL, Knoll JHM, Meyerson M and Weinberg RA: Inhibition of telomerase limits the growth of human cancer cells. Nat Med 5: 1164-1170, 1999.

44. Zhang X, Mar V, Zhou W, Harrington L and Robinson MO: Telomere shortening and apoptosis in telomerase-inhibited human tumor cells. Gene Dev 13: 2388-2399, 1999.

45. Mergny JL and Helene C: G-quadruplex DNA: a target for drug design. Nat Med 4: 1366-1367, 1998. 